\title{
Development of a Model of the ASTM E 84 Steiner Tunnel Test
}

\author{
MARC JANSSENS, JASON HUCZEK, and ANTHONY SAUCEDA \\ Fire Technology Department \\ Southwest Research Institute ${ }^{\circledR}$ \\ 6220 Culebra Road \\ San Antonio, TX 78238, USA
}

\begin{abstract}
Several calculation methods have been developed to predict ASTM E 84 Steiner tunnel test performance based on cone calorimeter data. Most of these methods have significant limitations because they were developed for specific types of products. This motivated the development of a more general mathematical model of the Steiner tunnel test. This paper describes the physical basis of the new model and illustrates its predictive capability on the basis of the experimental data that were obtained for twelve construction products with widely varying reaction-to-fire characteristics.
\end{abstract}

KEYWORDS: cone calorimeter, flame spread, modeling, smoke, Steiner tunnel

\section{NOMENCLATURE LISTING}

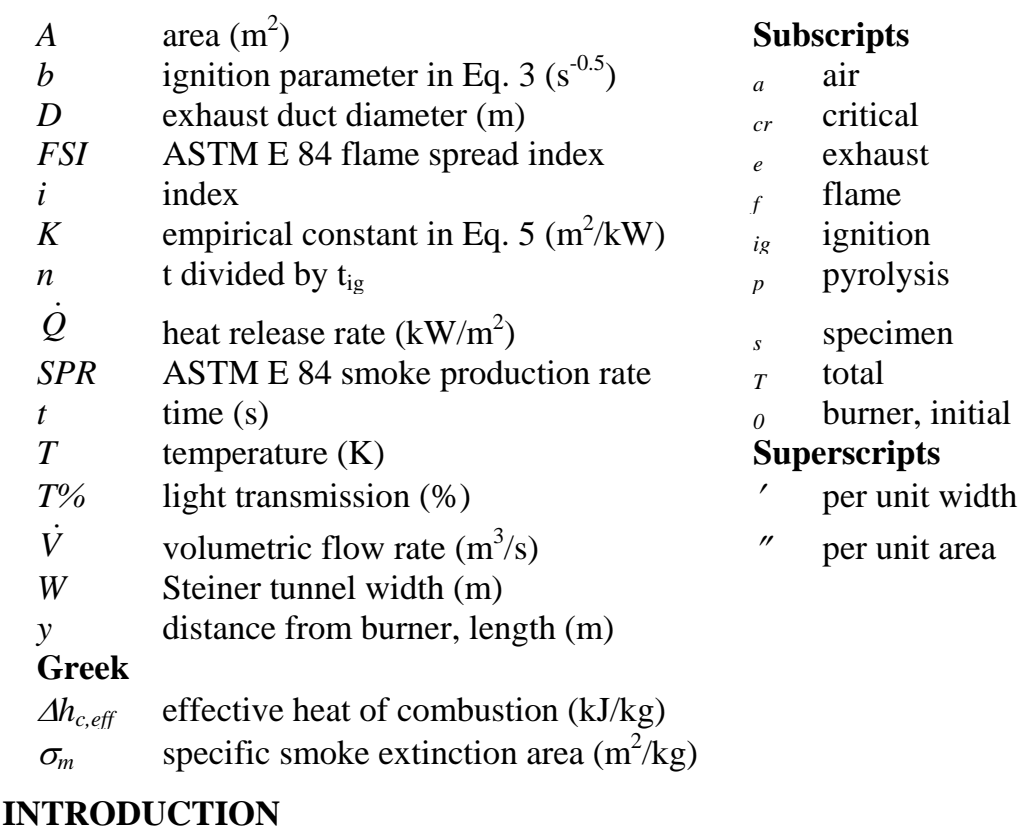

The fire hazard of interior finish materials is primarily due to the potential for rapid wind-aided flame spread over the surface. For this reason, reaction-to-fire requirements for interior finish materials in U.S. building codes are primarily based on performance in a wind-aided flame spread test. The apparatus of this test is often referred to as the Steiner tunnel. The Steiner tunnel test is described in ASTM E 84.

Since the Steiner tunnel test requires approximately $4 \mathrm{~m}^{2}$ of material, it is often not practical to use an experimental approach to develop products that have to meet specific test performance requirements. The test is not suitable for quality control for the same reason. To address this problem, a number of correlations and models have been developed to predict Steiner tunnel test performance on the basis of data from a small-scale test such as the cone calorimeter [1-10]. Most of these predictive methods have significant limitations because they were developed for specific types of products. This motivated the development of a more general mathematical model of the Steiner tunnel test. This model forms the subject of this paper. 


\section{THE STEINER TUNNEL TEST}

A photograph of the test apparatus is shown in Fig. 1. It consists of a long tunnel-like enclosure measuring $8.7 \times 0.45 \times 0.31 \mathrm{~m}$. The test specimen is $7.6 \mathrm{~m}$ long and $0.51 \mathrm{~m}$ wide, and is mounted in the ceiling position. It is exposed at one end, designated as the burner end, to a $79 \mathrm{~kW}$ gas burner. There is a forced draft through the tunnel from the burner end with an average initial air velocity of $1.2 \mathrm{~m} / \mathrm{s}$. The measurements consist of flame spread over the surface and smoke obscuration in the exhaust duct of the tunnel. Test duration is 10 minutes.

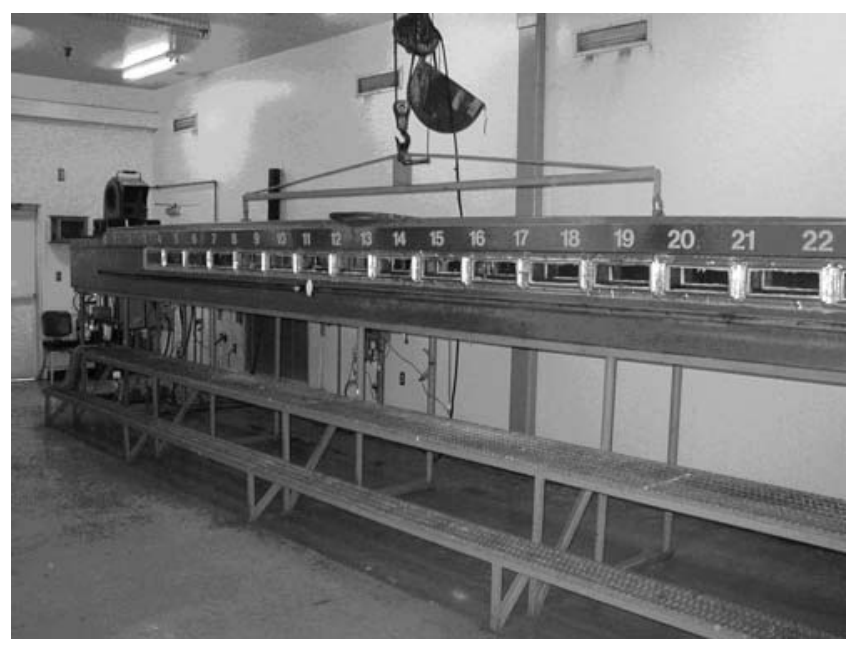

Fig. 1. Steiner tunnel test apparatus.

A flame-spread index (FSI) is calculated on the basis of the area under the curve of flame tip location versus time as follows:

$F S I= \begin{cases}0.0282 A_{T} & \text { for } A_{T} \leq 1783 \mathrm{~m} . \mathrm{s} \\ \frac{89611}{3566-A_{T}} & \text { for } A_{T}>1783 \mathrm{~m} . \mathrm{s}\end{cases}$

$A_{T}$ is calculated based on the flame extension, i.e., the distance of the flame tip from the burner minus the length of the burner flame. It is important to note that flame recession is ignored in the calculation of $A_{T}$. For example, Fig. 2 illustrates the flame extension measured in a test on polyisocyanurate foam (solid line) conducted at Southwest Research Institute $\left(\mathrm{SwRI}^{\circledR}\right)$. The flame quickly spreads to a maximum relative distance of $2.93 \mathrm{~m}$, but starts to recede after approximately one minute. The FSI in this case is calculated on the basis of the hatched area. The FSI is 0 for an inert board, and is normalized to approximately 100 for red oak flooring. The flame extension for red oak flooring is also shown in Fig. 2 (dashed line).

A Smoke Developed Index $(S D I)$ is calculated on the basis of the area under the smoke obscuration versus time curve:

$S D I=\frac{\left(\int_{0}^{10 \min }(100-T \%) d t\right)}{\left(\int_{0}^{10 \min }(100-T \%) d t\right)_{\text {Rest Specimen }}} \times 100$

An example of a measured light obscuration curve is shown in Fig. 3. 


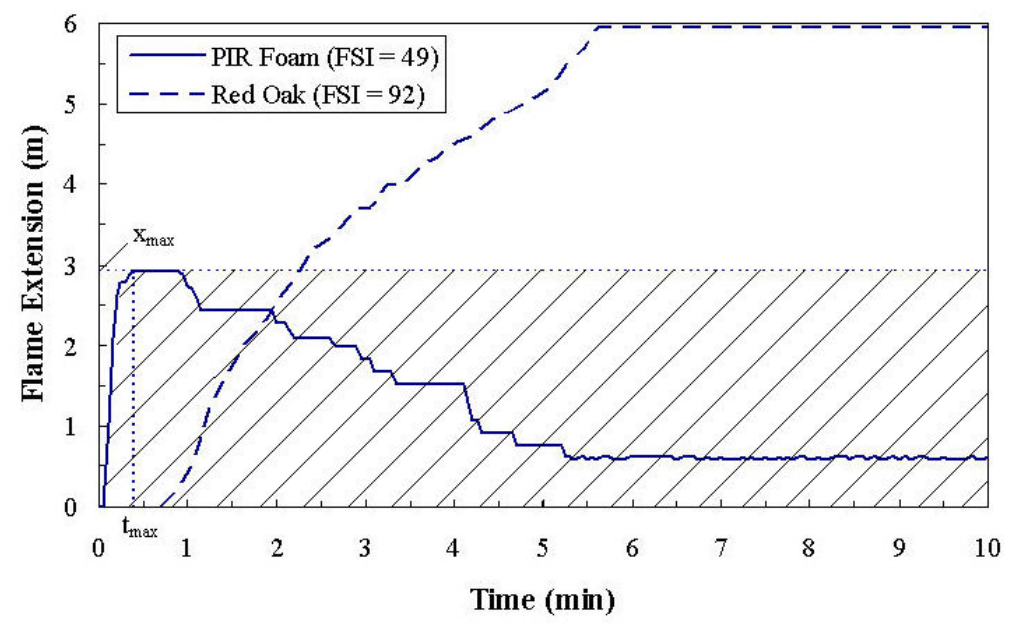

Fig. 2. ASTM E $84 A_{T}$ calculation for polyisocyanurate foam

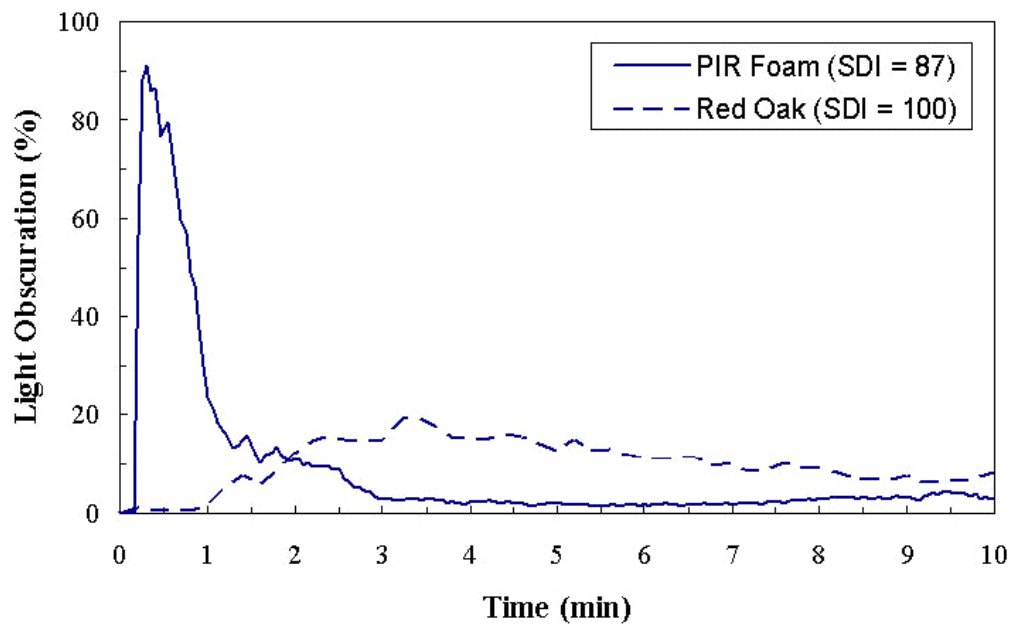

Fig. 3. ASTM E 84 SDI calculation for polyisocyanurate foam.

The classification of linings in the model building codes is based on the FSI and SDI. There are three classifications: Class A for products with $F S I \leq 25$, Class B for products with $25<F S I \leq 75$, and Class C for products with $75<F S I \leq 200$. For all classes the $S D I$ cannot exceed 450 . Class A products are generally permitted in enclosed vertical exits. Class B products can be used in exit access corridors, and Class $\mathrm{C}$ products are allowed in other rooms and areas.

\section{PREDICTING STEINER TUNNEL TEST PERFORMANCE}

\section{Thermal Environment in the Steiner Tunnel}

To model the performance of a product in the Steiner tunnel test, it is necessary to know the thermal environment, in particular the incident heat flux along the length of the specimen. Parker conducted a comprehensive investigation of the fire environment in the Steiner tunnel test [11]. Fig. 4 shows the incident heat flux measured by Parker as a function of distance on an asbestos-cement board after 20 minutes of exposure to the $79-\mathrm{kW}$ burner flame. The heat flux peaks at approximately $43 \mathrm{~kW} / \mathrm{m}^{2}$ at $0.58 \mathrm{~m}$ from the burner. The heat flux quickly drops below $10 \mathrm{~kW} / \mathrm{m}^{2}$ beyond the burner flame tip. Since these data were obtained after 20 minutes of exposure, incident heat fluxes during the initial stages of the test are expected to be somewhat lower as the tunnel walls have not had the time to heat up to equilibrium. 
Figure 5 shows Parker's incident heat flux measurements as a function of distance on an asbestos-cement board after 20 minutes of exposure to an auxiliary methane burner flame covering the entire $7.32 \mathrm{~m}$ length of the tunnel. The incident heat flux was measured at four locations: 2.44, 3.66, 4.88 and 7.32 m. The highest incident heat flux of approximately $66 \mathrm{~kW} / \mathrm{m}^{2}$ was measured at the first location. Again, since these data were obtained after 20 minutes of exposure, heat fluxes are expected to be lower in an actual test. This might be compensated for if the flame from the burning specimens has a higher soot concentration and/or temperature than the methane flame used by Parker.

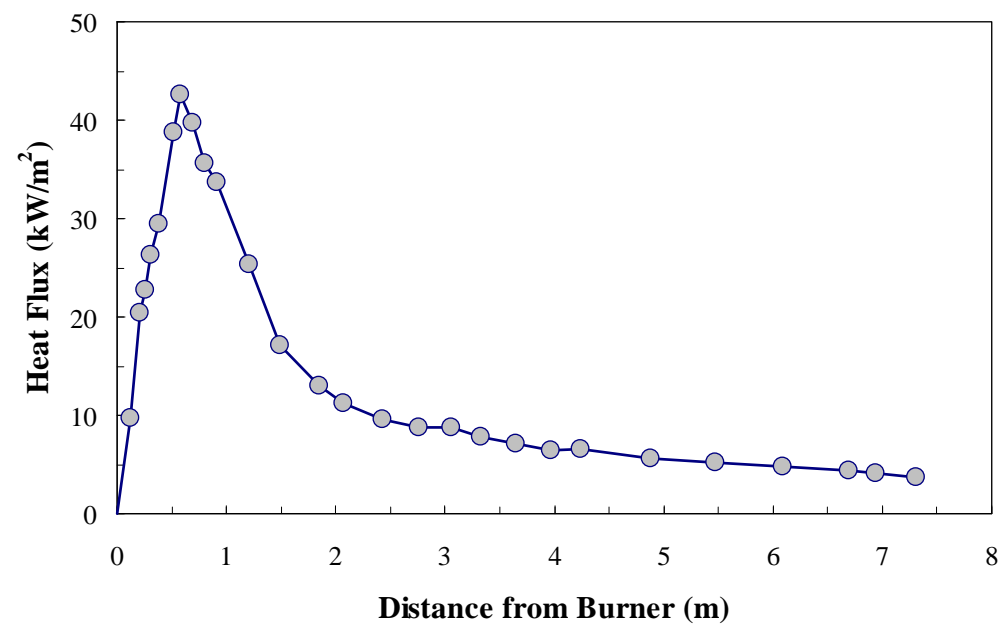

Fig. 4. Incident heat flux from the burner flame in the Steiner tunnel test.

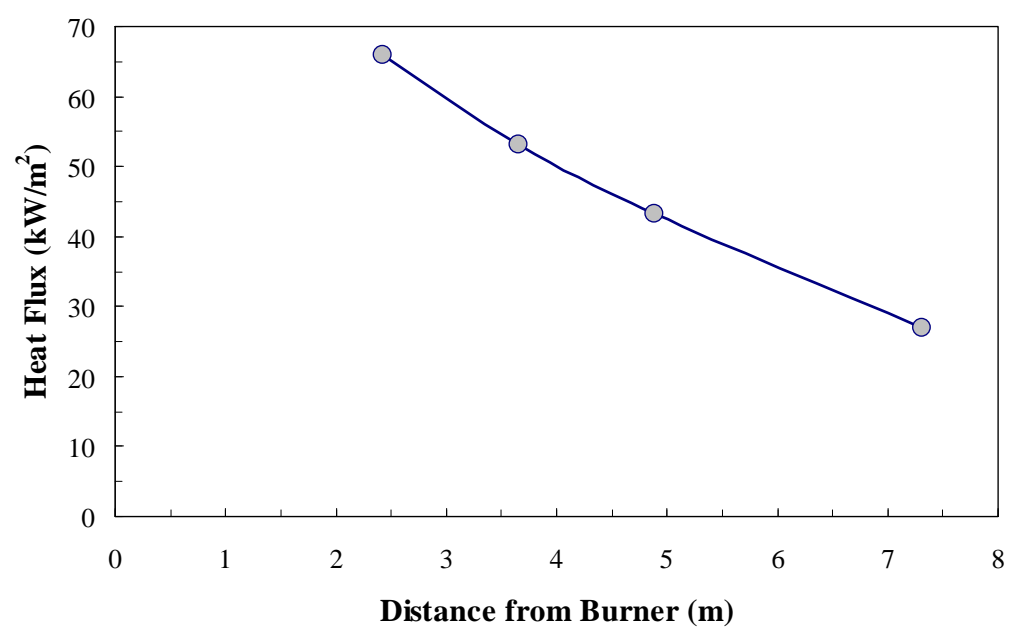

Fig. 5. Incident heat flux to a tunnel test specimen fully engulfed in flame.

\section{Predicting Ignition Time}

The time to ignition in the Steiner tunnel test of a material can be calculated based on the following equation:

$t_{i g}=\left(\frac{\dot{q}_{c r}^{\prime \prime}}{b \dot{q}_{b}^{\prime \prime}}\right)^{2}$ 
This equation is based on the assumption that the incident heat flux from the burner flame is uniform over the heated area and equal to $\dot{q}_{b}^{\prime \prime}$. The value of $b$ for a material is obtained from an analysis of ignition times $\left(t_{i g}\right)$ measured at different heat fluxes $\left(\dot{q}_{e}^{\prime \prime}\right)$ in the cone calorimeter or similar device. It is equal to the slope of the best fitting line through the ignition data points in a chart of $\dot{q}_{c r}^{\prime \prime} / \dot{q}_{e}^{\prime \prime}$ vs. $\sqrt{t_{i g}}$, where $\dot{q}_{c r}^{\prime \prime}$ is the critical heat flux for ignition [12]. In fact, Eq. 3 was used to determine the value of $\dot{q}_{b}^{\prime \prime}$ that results in the best overall agreement between predicted and measured ignition times in the Steiner tunnel test for twelve materials (see below). The resulting value for $\dot{q}_{b}^{\prime \prime}$ was $35 \mathrm{~kW} / \mathrm{m}^{2}$. This is consistent with Parker's incident heat flux measurements shown in Fig. 4.

\section{Predicting Flame Spread and Smoke Development}

A simplified model was developed to calculate flame propagation and smoke development in the Steiner tunnel test. The burner location is chosen as the origin for the distance along the specimen, $y$. The front edge of the specimen is located between 0 and $0.3 \mathrm{~m}$ upstream of the burner center line, depending on the length of the specimen. The specimen extends approximately $7.32 \mathrm{~m}$ beyond the burner location (see Fig. 6). At the start of a test, the burner flame impinges on the specimen and extends downstream over a distance $y_{f, 0}=1.37 \mathrm{~m}$. At $t=t_{i g}$ the specimen area heated by the burner flame ignites. It is assumed that the flame length due to the specimen is additive with the tunnel burner flame:

$$
y_{f}=y_{f, s}+y_{f, 0}
$$

The flame extension due to the burning specimen can be estimated from its heat release rate:

$y_{f, s}=K \dot{Q}^{\prime}=K \dot{Q}^{\prime \prime} y_{p}$
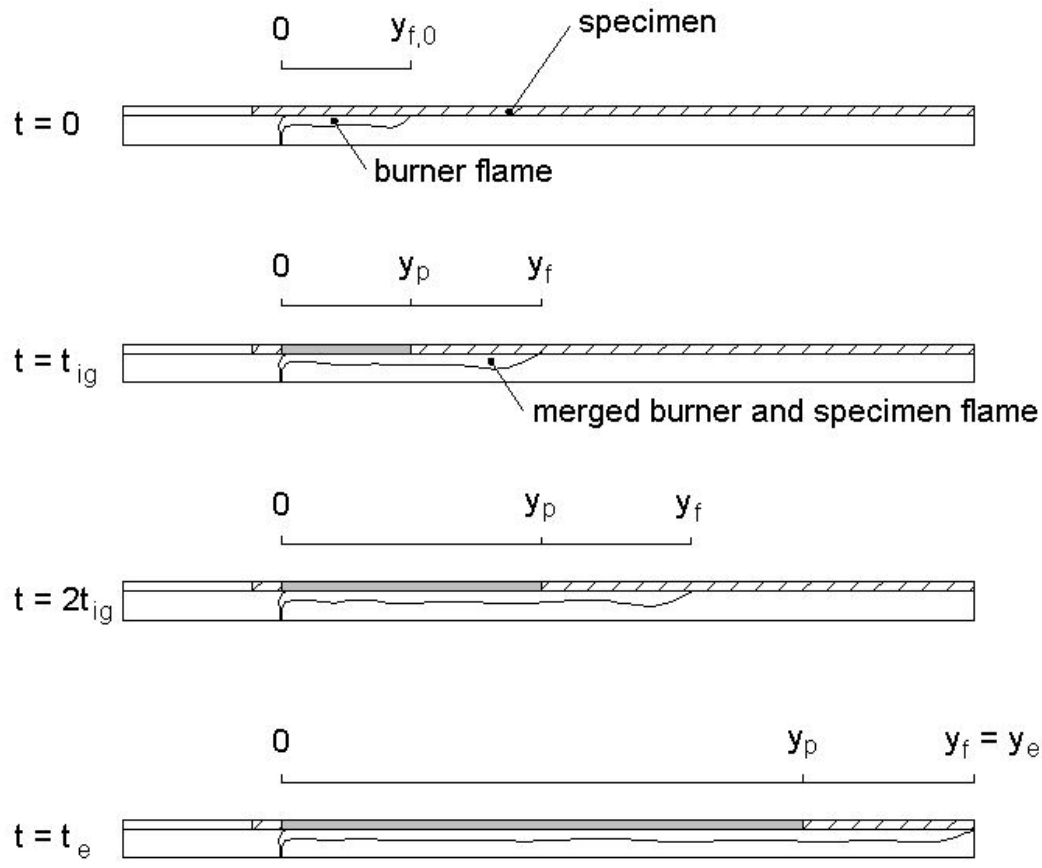

Fig. 6. Flame propagation in the Steiner tunnel test. 
Parker [11] measured flame length in Steiner tunnel tests with an auxiliary gas burner and with different types of specimens (see Fig. 7). Based on this data, Parker suggested a value of $K=0.022 \mathrm{~m}^{2} / \mathrm{kW}$. This value is much higher than what is reported in more recent studies of turbulent diffusion flames from gas burners against walls [13]. It is also inconsistent with the $1.37 \mathrm{~m}$ flame length of the $79-\mathrm{kW}$ burner flame. The burner consists of two 19-mm NPT $90^{\circ}$ elbows connected to a tee. The burner gas is discharged through the open ends of the elbows, which are facing upward and located approximately $190 \mathrm{~mm}$ (7.5 in.) below the specimen surface. Based on Heskestad's flame height correlation [14], it can be estimated that the flame has released $20 \%$ of its heat when it hits the specimens and is deflected in the downstream direction. Based on a residual heat release rate of $64 \mathrm{~kW}$, a tunnel width of $0.46 \mathrm{~m}$ and a flame length of $1.37 \mathrm{~m}, K$ is approximately equal to $0.01 \mathrm{~m}^{2} / \mathrm{kW}$. This value is consistent with the literature and is used in the model.

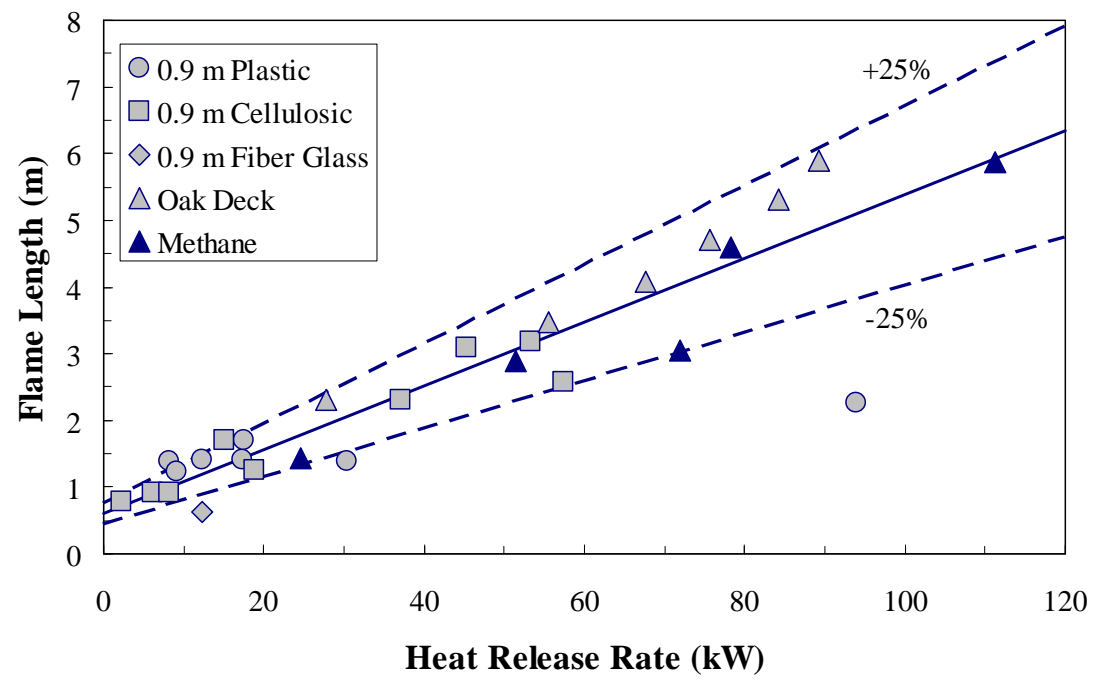

Fig. 7. Flame length vs. heat release rate in the Steiner tunnel measured by Parker.

As mentioned before, at $t=t_{i q}$ the area initially heated by the burner flame ignites. As a result, the pyrolysis front progresses to $y_{f, 0}$ and the flame length increases according to Eq. 4 and Eq. 5 . Assuming that the incident heat flux from the specimen flame is $35 \mathrm{~kW} / \mathrm{m}^{2}$, the area between $y_{p}$ and $y_{f}$ at $t=t_{i g}$ will ignite at $t=t_{i g}$. As a result the pyrolysis front and flame tip will advance again. Eventually the flame will reach the end of the tunnel, unless the heat release rate from the burning segments decreases sufficiently to cause the flame tip to stagnate or recede.

It is assumed that the heat release rate in the tunnel is equal to that measured in the cone calorimeter at a heat flux level that is representative of the thermal environment in the tunnel. Since the pyrolysis front and flame tip are considered to advance discretely at times equal to multiples of $t_{i g}$ and are assumed to remain at the same location in between, it is not possible to account for changes in the heat release rate over shorter time increments. An Excel VBA macro was written to transform the dynamic heat release rate curve measured in the cone calorimeter into a format suitable for input into the model. The macro calculates the average heat release rate for subsequent periods each of equal duration equal to $t_{i g}$, i.e., the ignition time calculated for the tunnel test.

The total heat release rate from the burning specimen per unit width is then given by:

$\dot{Q}^{\prime}\left(n t_{i g}\right)=\sum_{i=1}^{n} \dot{Q}^{\prime \prime}\left((n-i) t_{i g}\right)\left[y_{p}\left(i t_{i g}\right)-y_{p}\left((i-1) t_{i g}\right)\right]$ 
The smoke production rate can be estimated from the heat release rate using the following equation:

$\operatorname{SPR}\left(n t_{i g}\right)=\frac{W \dot{Q}^{\prime}\left(n t_{i g}\right) \sigma_{m}}{\Delta h_{C, e f f}}$

Both $\sigma_{m}$ and $\Delta h_{c, \text { eff }}$ are measured in the cone calorimeter. The light transmission can be determined as follows:

$T \%\left(n t_{i g}\right)=100 / \exp \left(\frac{293 \times S P R\left(n t_{i g}\right) \times D}{\dot{V}_{a} T_{e}\left(n t_{i g}\right)}\right)$

The inflow rate of air into the tunnel is held constant during a test. Parker developed the following correlation to estimate the gas temperature in the exhaust duct:

$T_{e}\left(n t_{i g}\right)=31+2.5\left[79+W \dot{Q}^{\prime}\left(n t_{i g}\right)\right]$

The final question is what heat flux level to use for the cone calorimeter tests? This question is addressed in the next section.

\section{Selecting a Representative Heat Flux Level for Cone Calorimeter Testing}

Parker's measurements in Fig. 5 seem to indicate that $50 \mathrm{~kW} / \mathrm{m}^{2}$ is a reasonable choice as a "representative" heat flux level for cone calorimeter testing. To verify this the model was used to simulate Steiner tunnel test performance of Douglas fir plywood based on cone calorimeter data at $50 \mathrm{~kW} / \mathrm{m}^{2}$. It is important to note that the macro which converts the heat release rate data removes the second peak. This is because the second peak in the cone calorimeter is due to the fact that specimens are backed with ceramic fiber blanket. Tunnel specimens are backed with fiber cement board, and the second peak is therefore not expected to occur. A comparison between calculations and measurements indicated that the model significantly overestimates the FSI and SDI when input data are based on cone calorimeter tests at $50 \mathrm{~kW} / \mathrm{m}^{2}$.

Since the average heat flux from the burner flame, at least in the initial minutes of a test, appears to be approximately $35 \mathrm{~kW} / \mathrm{m}^{2}$, it was logical to find out if this would be a better choice. The calculated FSI and SDI were still (much) higher than the measured values, and a third simulation was performed with cone calorimeter data obtained at $25 \mathrm{~kW} / \mathrm{m}^{2}$. The predicted $F S I$ and $S D I$ in this case were very close to the measured values. The reasons why the low heat flux works best are not clear.

\section{MODEL VALIDATION}

\section{Products Tested}

Triplicate tests were performed on construction products in the Steiner tunnel and at several heat flux levels in the cone calorimeter. Table 1 provides some information about the products that were tested. Wall coverings were adhered to $12.7-\mathrm{mm}$ ( $1 / 2 \mathrm{in}$.) Type X gypsum board. The composite density is that of the wall covering adhered to the substrate.

\section{Ignition Time Predictions}

A comparison between predicted and measured ignition times is shown in Fig. 8. The numeric values are given in Table 2. 
Table 1. Products tested.

\begin{tabular}{|c|c|c|c|c|c|}
\hline Product & Substrate & $\begin{array}{r}\text { Density } \\
\left(\mathrm{kg} / \mathrm{m}^{3}\right) \\
\end{array}$ & $\begin{array}{c}\text { Thickness } \\
\text { (mm) } \\
\end{array}$ & $\begin{array}{c}\text { Moisture } \\
\text { Content } \\
(\%) \\
\end{array}$ & \begin{tabular}{|c|} 
Composite \\
Density \\
$\left(\mathbf{k g} / \mathbf{m}^{3}\right)$ \\
\end{tabular} \\
\hline Douglas Fir Plywood & $\mathrm{NA}^{\mathrm{a}}$ & 535 & 11.9 & 10.0 & 535 \\
\hline FRT Douglas Fir Plywood & $\mathrm{NA}^{\mathrm{a}}$ & 615 & 11.9 & 10.0 & 615 \\
\hline Glassfiber Reinforced Plastic & $\mathrm{NA}^{\mathrm{a}}$ & 1420 & 2.79 & $\mathrm{NM}^{\mathrm{b}}$ & 1420 \\
\hline Type X Gypsum Board & $\mathrm{NA}^{\mathrm{a}}$ & 745 & 12.7 & $\mathrm{NM}^{\mathrm{b}}$ & 745 \\
\hline Polyisocyanurate Foam & $\mathrm{NA}^{\mathrm{a}}$ & 28 & 38.1 & $\mathrm{NM}^{\mathrm{b}}$ & 28 \\
\hline Vinyl Wallcovering & Type X Gypsum Board & 1040 & 0.33 & $\mathrm{NM}^{\mathrm{b}}$ & 750 \\
\hline Textile Wallcovering & Type X Gypsum Board & 185 & 0.25 & $\mathrm{NM}^{\mathrm{b}}$ & 710 \\
\hline Paper Wallcovering & Type X Gypsum Board & 1200 & 0.75 & $\mathrm{NM}^{\mathrm{b}}$ & 750 \\
\hline Oriented Strand Board 1 & $\mathrm{NA}^{\mathrm{a}}$ & 735 & 11.4 & 9.0 & 735 \\
\hline Oriented Strand Board 2 & $\mathrm{NA}^{\mathrm{a}}$ & 680 & 11.7 & 8.8 & 680 \\
\hline White Pine Planks & $\mathrm{NA}^{\mathrm{a}}$ & 525 & 18.8 & 10.3 & 525 \\
\hline White Oak Planks & $\mathrm{NA}^{\mathrm{a}}$ & 840 & 18.8 & 8.5 & 840 \\
\hline
\end{tabular}

${ }^{a}$ No substrate used

${ }^{\mathrm{b}}$ Not measured

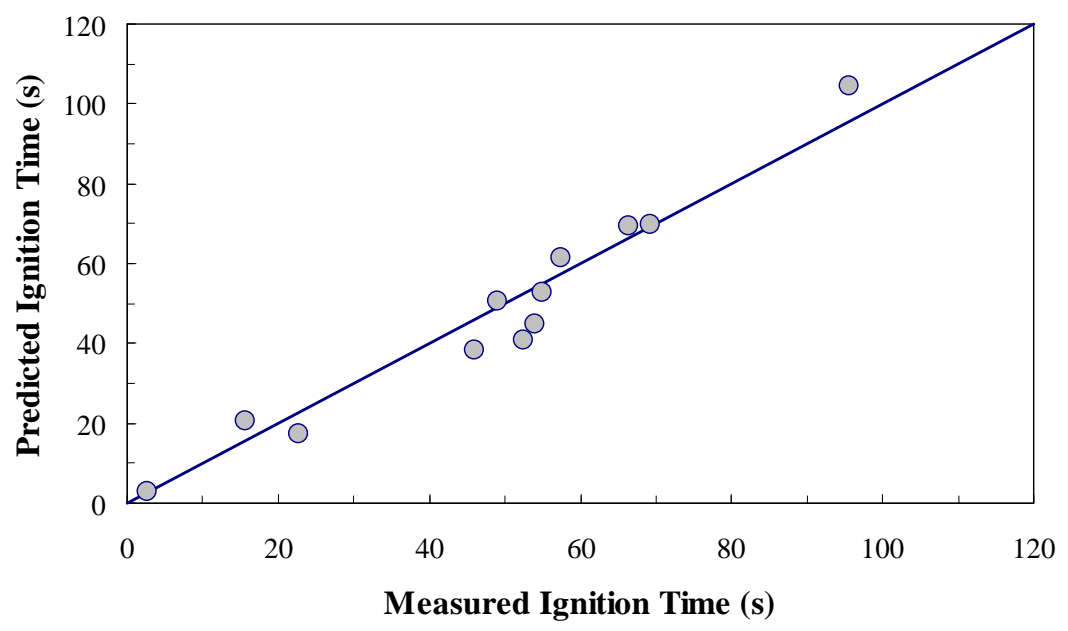

Fig. 8. Predicted vs. measured ignition time in the Steiner tunnel test.

\section{Flame Spread Index and Smoke Developed Index Predictions}

Figure 9 and Fig. 10 show a comparison between calculated and measured FSI and SDI values, respectively. Table 3 summarizes the results of the analysis. It can be observed from Fig. 9 that the FSI predictions are conservative. The measured classification is equal the predicted classification, except for two products, the polisocyanurate foam and the first oriented strand board. The predicted FSI for the latter slightly exceeds 200. Because the ignition time of the polyisocyanurate foam is very short, the model predicts that flames spread quickly to the end of the tunnel. The anomalous behavior of exposed plastic foam materials in the Steiner tunnel test is well known [2]. Figure 10 shows that the predicted SDI classification is consistent with that based on the measurements except for the glassfiber reinforced plastic. The scatter for the smoke developed predictions is higher than that of the flame spread predictions, which is not unusual. 
Table 2. Predicted vs. measured ignition times based on burner flame flux of $35 \mathrm{~kW} / \mathrm{m}^{2}$.

\begin{tabular}{|l|c|c|c|c|}
\hline Material ID & $\begin{array}{c}\dot{q}_{c r}^{\prime \prime} \\
\left(\mathbf{k W / \mathbf { m } ^ { 2 } )}\right.\end{array}$ & $\begin{array}{c}\boldsymbol{b} \\
\left(\mathbf{s}^{-\mathbf{0 . 5}}\right)\end{array}$ & $\begin{array}{c}\text { Predicted } \boldsymbol{t}_{\boldsymbol{i}} \\
\mathbf{( s )}\end{array}$ & $\begin{array}{c}\text { Measured } \boldsymbol{t}_{\boldsymbol{i}} \\
\mathbf{( s )}\end{array}$ \\
\hline Douglas Fir Plywood & 14.0 & 0.0562 & 51 & 49 \\
\hline FRT Douglas Fir Plywood & 18.0 & 0.0615 & 70 & 69 \\
\hline Glassfiber Reinforced Plastic & 12.0 & 0.0412 & 69 & 66 \\
\hline Type X Gypsum Board & 29.0 & 0.0811 & 104 & 96 \\
\hline Polyisocyanurate Foam (w/o foil) & 12.0 & 0.2010 & 3 & 3 \\
\hline Vinyl Wallcovering & 21.0 & 0.1445 & 17 & 23 \\
\hline Textile Wallcovering & 23.0 & 0.1447 & 21 & 16 \\
\hline Paper Wallcovering & 22.0 & 0.0864 & 53 & 55 \\
\hline Oriented Strand Board 1 & 15.0 & 0.0640 & 45 & 54 \\
\hline Oriented Strand Board 2 & 14.0 & 0.0625 & 41 & 53 \\
\hline White Pine Planks & 16.0 & 0.0740 & 38 & 46 \\
\hline White Oak Planks & 17.0 & 0.0619 & 62 & 58 \\
\hline
\end{tabular}

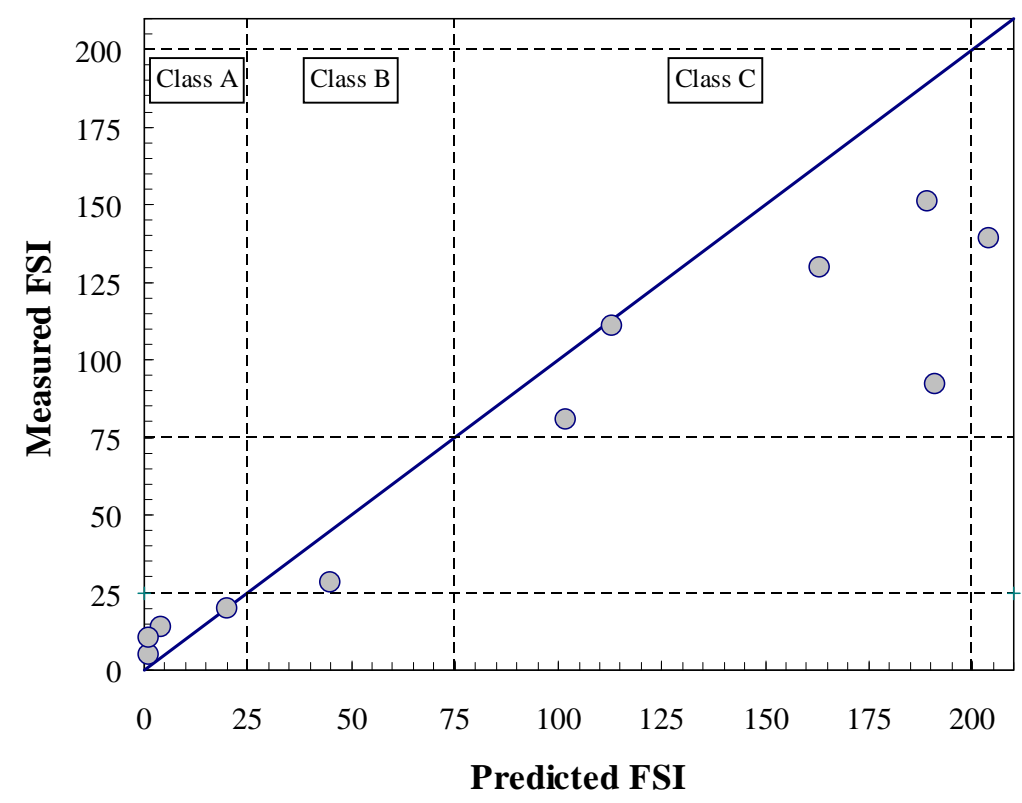

Fig. 9. Comparison between predicted and measured FSI values. 


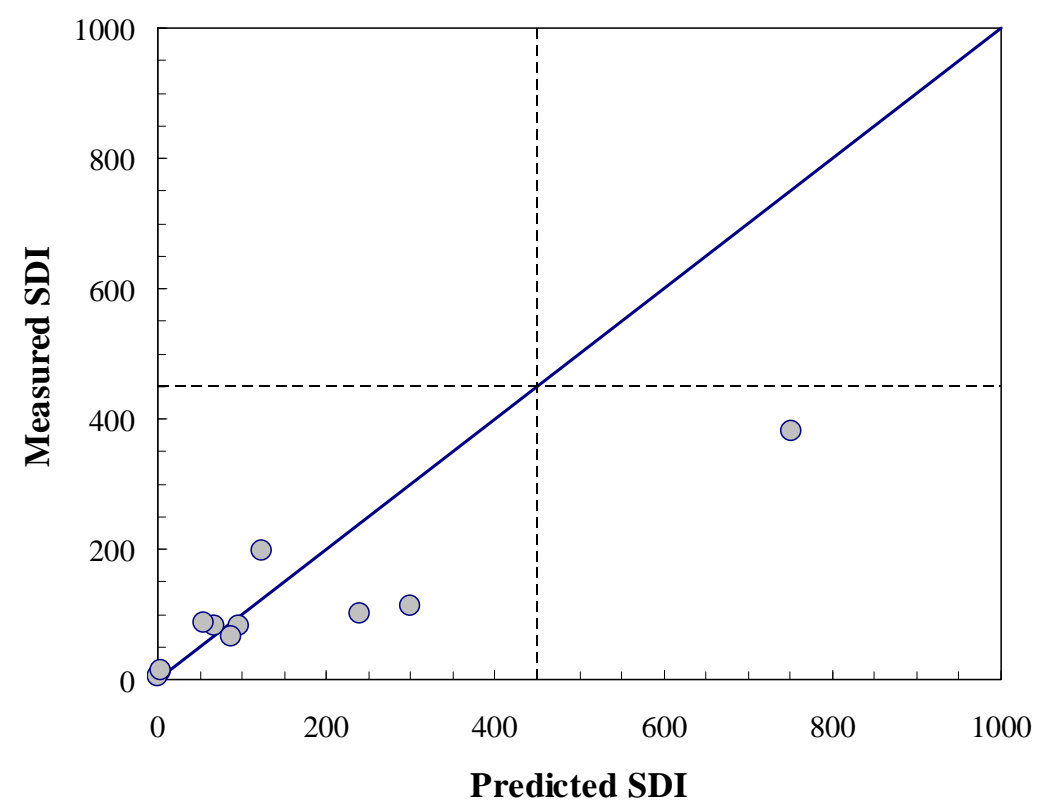

Fig. 10. Comparison of predicted and measured SDI values.

Table 3. Comparison of predicted and measured FSI and SDI values.

\begin{tabular}{|c|c|c|c|c|c|c|}
\hline Product & \begin{tabular}{|c} 
Measured \\
FSI
\end{tabular} & \begin{tabular}{|c|} 
Predicted \\
FSI
\end{tabular} & \begin{tabular}{|c|} 
Measured \\
SDI
\end{tabular} & \begin{tabular}{|c|} 
Predicted \\
SDI
\end{tabular} & \begin{tabular}{|c|}
$\begin{array}{c}\text { Measured } \\
\text { Class }\end{array}$ \\
\end{tabular} & \begin{tabular}{|c} 
Predicted \\
Class
\end{tabular} \\
\hline Douglas Fir Plywood & 111 & 113 & 83 & 96 & $\mathrm{C}$ & $\mathrm{C}$ \\
\hline FRT Douglas Fir Plywood & 14 & 4 & 11 & 4 & $\bar{A}$ & A \\
\hline Glassfiber Reinforced Plastic & 130 & 163 & 380 & 752 & $\mathrm{C}$ & $\overline{\mathrm{U}}$ \\
\hline Type X Gypsum Board & 5 & 1 & 4 & 0 & A & A \\
\hline Polyisocyanurate Foam & 54 & 661 & 83 & 67 & $\bar{B}$ & $\bar{U}$ \\
\hline Vinyl Wallcovering & 28 & 45 & 66 & 87 & $\bar{B}$ & $\bar{B}$ \\
\hline Textile Wallcovering & 20 & 20 & 86 & 55 & $\bar{A}$ & $\bar{A}$ \\
\hline Paper Wallcovering & 10 & 1 & 14 & 3 & $\mathrm{~A}$ & $\bar{A}$ \\
\hline Oriented Strand Board 1 & 139 & 204 & 102 & 240 & $\mathrm{C}$ & $\bar{U}$ \\
\hline Oriented Strand Board 2 & 151 & 189 & 114 & 299 & $\mathrm{C}$ & $\mathrm{C}$ \\
\hline White Pine Planks & 92 & 191 & 198 & 124 & $\mathrm{C}$ & $\mathrm{C}$ \\
\hline White Oak Planks & 81 & 102 & 63 & 50 & $\bar{C}$ & $\bar{C}$ \\
\hline
\end{tabular}

\section{CONCLUSIONS}

An extensive set of cone calorimeter and Steiner tunnel test data have been obtained for a range of construction products with widely varying reaction-to-fire characteristics. This data set will be invaluable for validation of a physics-based model of the Steiner tunnel test that will result from further development of the calculation method described in this paper. Specific recommendations for additional work are as follows:

- Improve the physical basis of the flame spread model for the Steiner tunnel test to eliminate the outliers in the FSI predictions.

- Revise the pertinent algorithms in the model to reduce the scatter in the smoke predictions and remove the outlier.

We intend to pursue these recommendations in the near future. 


\section{ACKNOWLEDGEMENT}

The authors would like to thank Mr. Les Richardson and Dr. James Mehaffey for allowing us to use the data obtained in the tests funded by Forintek Canada Corporation.

\section{REFERENCES}

[1] Parker, W., "Assessment of the Correlations between Laboratory and Full-Scale Experiments for the FAA Aircraft Fire Safety Program, Part 3: ASTM E 84.” National Bureau of Standards Report NBSIR 82-2564, Gaithersburg, MD, 1983.

[2] Quintiere, J., (1984) Some Factors Influencing Fire Spread over Room Linings and in the ASTM E 84 Tunnel Test, Fire and Materials, 9, 65-74, doi:10.1002/fam.810090203.

[3] Janssens, M., "Modeling the E84 Tunnel Test for Wood Products," Fire and Materials, 1st International Conference, Interscience Communications Ltd., London, England, 1992, pp. 33-42.

[4] Dowling, K. and E. Feske, "Using the Cone Calorimeter to Predict the Fire Performance of Rigid Polyurethane Foams in the Steiner Tunnel, and Comparison with European Standard Tests," Thirty-Fifth Annual Polyurethane Technical Marketing Conference, 1994, pp. 357-363.

[5] Stevens, M., V. Voruganti and R. Rose, "Correlation of Small Scale Fire Tests to ASTM E-84 Tunnel Performance for Thermoset Resin Systems," 4th International Fire and Materials Conference and Exhibition, Interscience Communications Ltd.,, London, England, 1995, pp. 319327.

[6] Sheppard, D. and P. Gandhi, (1996) Estimating Smoke Hazard from Steiner Tunnel Smoke Data, Fire Technology, 32, 65-75, doi:10.1007/BF01040758.

[7] Hirschler, M., "Smoke Obscuration in the Steiner Tunnel Test: Can It Be Predicted?” TwentyThird International Conference on Fire Safety, Product Safety Corporation, Millbrae, CA, 1997.

[8] Stevens, M., “Cone Calorimeter as a Screening Test for ASTM E-84 Tunnel Test," $5^{\text {th }}$ International Fire and Materials Conference, Interscience Communications Ltd., London, England, 1998, pp. 147-151.

[9] Dietenberger, M. and R. H. White, "Reaction-to-Fire Testing and Modeling for Wood Products," Twelfth Annual BCC Conference on Flame Retardancy, Business Communications Co., Norwalk, CT, 2001.

[10] White, R. and M. Dietenberger "Cone Calorimeter Evaluation of Wood Products,” Fifteenth Annual BCC Conference on Flame Retardancy, Business Communications Co., Norwalk, CT, 2004.

[11] Parker, W., "An Investigation of the Fire Environment in the ASTM E-84 Tunnel Test," National Bureau of Standards Technical Note 945, Gaithersburg, MD, 1977.

[12] Quintiere, J. and M. Harkleroad, "New Concepts for Measuring Flame Spread Properties," National Bureau of Standards Report NBSIR 84-2943, Gaithersburg, MD, 1984.

[13] Hasemi, Y., and T. Tokunaga, "Modeling of Turbulent Diffusion Flames and Fire Plumes for the Analysis of Fire Growth," 21st National Heat Transfer Conference, Fire Dynamics and Heat Transfer, ASME, 1983, pp. 37-45.

[14] Heskestad, G. (2002). "Fire Plumes, Flame Height and Air Entrainment," The SFPE Handbook of Fire Protection Engineering ( ${ }^{\text {rd }}$ ed), DiNenno P.J. (ed.), National Fire Protection Association, Quincy, MA, 2002, p. 2/1. 
